\title{
Acceptance of Corporate Blogs for Collaboration and Knowledge Sharing
}

\author{
Santiago Iglesias-Pradas (10), Ángel Hernández-García (10ª, and Pedro Fernández-Cardador ${ }^{\mathrm{b}}$ \\ aDepartamento de Ingeniería de Organización, Administración de Empresas y Estadística, Universidad Politécnica de Madrid, Madrid, Spain; \\ ${ }^{\mathrm{b}}$ Airbus Defence and Space, Madrid, Spain
}

\begin{abstract}
This study investigates employees acceptance of corporate Web 2.0 applications for collaboration and knowledge sharing. Results show that altruism, managerial support, and perceived usefulness are good predictors of the intention to use corporate blogs as tools for collaboration and knowledge sharing. The study further explores differences between employees from companies with low and high adoption rates, and uses prediction-oriented segmentation to unveil two different paths to adoption of Web 2.0 collaborative tools in companies.
\end{abstract}

\section{KEYWORDS}

Collaboration; corporate blogs; knowledge sharing; TAM; technology acceptance; Web 2.0

\section{Introduction}

Knowledge sharing in organizations is essential because it enables organizations to reduce redundant learning efforts and enhance innovative performance (Calantone, Cavusgil, \& Zhao, 2002; Martinez-Conesa, Soto-Acosta, \& Carayannis, 2017; Scarbrough, 2003; Syed-Ikhsan \& Rowland, 2004). Boer (2005) conceptualized knowledge sharing as a social-relational process through which individuals try to establish a shared understanding about reality and the potential ability to transform this understanding into collaborative actions, which yield performance by different signs and tools. This definition characterizes knowledge sharing as a communication process that is socially situated, and stresses some important aspects of knowledge sharing, such as its potential for collaboration through the use of signs (e.g., language and images) and tools (e.g., information technologies). Boer (2005) further pointed out that the creation of collective outcomes requires that members of the organization share their knowledge.

Knowledge sharing pursues the generation of new ideas and business opportunities through socialization and learning processes of knowledge workers (Lin \& Lee, 2006; Soto-Acosta, Popa, \& Palacios-Marqués, 2016). The selection of the appropriate technology to foster collaboration and knowledge exchanges is essential in order to better organize and structure the exchange mechanism in an effective and safe way. Web 2.0 technologies have become one of the most popular online communication and collaboration tools in everyday life, and also within organizations (Chai, Das, \& Rao, 2011; Soto-Acosta, Popa, \& PalaciosMarqués, 2017). Web 2.0 refers to a set of user-centric technologies whose value increases as the number of users increase (O'Reilly, 2005). The adaptation of the concept of Web 2.0 to business contexts is known as Enterprise 2.0 (McAfee, 2006). Entreprise 2.0 refers to the use of a set of tools-including blogs, wikis, mashups, tagging, and social networking-to enhance communication, collaboration, and knowledge sharing.

While Enterprise 2.0 tools are comparable in some ways to other types of information systems (e.g., Enterprise Resource Planning (ERP) systems, Customer Relationship Management (CRM) systems), they differ significantly in many other aspects. Web 2.0 tools are flexible: The same Web 2.0 tool may be used for very different purposes, and Web 2.0 applications tend to be less complex than legacy enterprise systems. These characteristics facilitate diffusion among employees and allow for lower initial investment for the company. Web 2.0 tools generally complement existing work practices in organizations; thus, unlike processoriented business systems, the use of Web 2.0 tools focuses on the support of communication and collaboration activities among individuals and workgroups, and their use is generally voluntary (Raeth, Urbach, Smolnik, Butler, \& Königs, 2010).

Nevertheless, and despite some consensus on the benefits from successful implementations of Web 2.0 technologies (Andriole, 2010), companies report significant

CONTACT Ángel Hernández-García angel.hernandez@upm.es $\Theta$ Departamiento de Ingeniería de Organización, Administración de Empresas y Estadística, Escuela Técnica Superior de Ingenieros de Telecomunicación, Universidad Politécnica de Madrid, Avenida Complutense 30, Despacho A-127, 28040 Madrid, Spain.

Color versions of one or more of the figures in the article can be found online at www.tandfonline.com/uism.

(c) 2017 Taylor \& Francis 